\title{
EDITORIAL
}

\section{AÑOS DE PSYKHE}

Junto con el presente número, Psykhe cumple 30 años. Desde su fundación en 1992 por el profesor de la Escuela de Psicología de la Pontificia Universidad de Chile, Jorge Gissi, Psykhe ha desarrollado una labor editorial ininterrumpida de la mano de diversos equipos editoriales consolidando progresivamente el proyecto editorial de la revista que es reconocida hoy a nivel nacional e internacional.

La contribución que ha realizado Psykhe al desarrollo y difusión de la disciplina psicológica y, en particular, de su investigación tanto en Chile como en Latinoamérica es palpable en la calidad de los artículos que en ella se publican. La diversidad de dichos trabajos, su rigurosidad, su relevancia tanto para la investigación como para su aplicación práctica, y la atingencia de las temáticas abordadas respecto de los distintos fenómenos emergentes que han desafiado a nuestra disciplina, dan cuenta de la contribución de autoras y autores de diversas partes del mundo, así como de las revisoras y revisores, que han colaborado con Psykhe en el proceso editorial.

No cabe duda de que el mundo ha cambiado bastante desde 1992. Cambios que han sido especialmente desafiantes durante estos últimos años en el contexto de la pandemia por Covid-19 que ha afectado la labor académica, y por consiguiente el trabajo editorial de esta y otras revistas. Durante estas tres décadas, Psykhe ha ido implementando diversos cambios, proponiendo nuevas formas de publicación, y ajustando sus procesos editoriales a estos nuevos escenarios. A nivel de la política editorial, la revista ha tomado como principio la publicación de artículos de investigación basados en evidencia, ya que creemos que la labor de la revista es difundir trabajos académicos que se sustentan en sólidos marcos conceptuales, y que, utilizando metodologías pertinentes, responden a preguntas relevantes para la psicología en sus distintas áreas. En la actualidad, la revista publica reportes de investigación, desarrollos metodológicos y revisiones sistemáticas. Además, la sección "Puntos de vista" permite convocar a investigadoras e investigadores consolidados a compartir perspectivas académicas sobre temáticas relevantes para la disciplina.

Otro aspecto definitorio de la política editorial es la rigurosa revisión por pares en formato de doble ciego. Quisiera aprovechar esta oportunidad para agradecer a todas y todos quienes han revisado artículos de manera desinteresada, con rigurosidad y generosidad; ustedes son parte fundamental del prestigio del cual Psykhe goza hoy. Del mismo modo, Psykhe ha tenido una preocupación continua por seguir de manera rigurosa estándares éticos de los artículos publicados. La publicación científica es importante en su originalidad y relevancia científica, pero también lo es desde su relevancia social, donde la psicología puede aportar en problemáticas que en diferentes ámbitos del quehacer social impactan en la vida y el bienestar de las personas.

Nuestros procesos editoriales también han ido revisándose y ajustándose continuamente, lo cual ha sido impulsado en parte por el creciente número de manuscritos que recibe la revista. De esta forma, recientemente la administración de la plataforma de la revista fue actualizada y alojada en el Sistema de Bibliotecas de la Pontificia Universidad Católica de Chile, aprovechando así el conocimiento y experticia del equipo que compone esta unidad, como también la infraestructura existente. De igual manera, a partir del presente número hemos actualizado nuestras normas de publicación a las normas APA 7a edición. Asimismo, hemos integrado en nuestra plataforma web plantillas para la preparación de los artículos, para agilizar nuestro proceso editorial y facilitar la adecuación de los manuscritos enviados al formato solicitado por la revista. Finalmente, quisiéramos comunicarles que a partir del presente número las publicaciones de la revista se realizarán en los meses de enero y julio de cada año para alinear los números de la revista con el inicio de cada semestre calendario.

Quisiera destacar también la colaboración que existe desde 2018 entre Psykhe y la Sociedad Científica de Psicología de Chile (SCP). Los resúmenes de las ponencias presentados en los congresos de la SCP han sido publicados en la revista, relevando así la calidad de la investigación que se realiza en nuestro país, y el fortalecimiento de redes colaborativas entre académicos y académicas de distintas universidades y regiones. Esperamos que esta alianza siga fortaleciéndose en los próximos años. 
$\mathrm{Al}$ cumplir estos 30 años de la revista, y rememorando lo que ha sido el trabajo y contribución continua de Psykhe a la psicología y al desarrollo de la investigación psicológica en nuestra región, quisiera destacar la labor que en cada periodo realizaron las y los editores que lideraron este proceso de crecimiento y consolidación: Jorge Gissi, Mariane Krause, Franco Simonetti, Neva Milicic, María Rosa Lissi, Patricio Cumsille y Marcela Cornejo. El trabajo editorial constituye un aspecto clave para que la investigación científica pueda ser transmitida e impacte tanto en los ámbitos académicos, profesionales, como en las distintas instancias de toma de decisiones. El trabajo comprometido de editoras y editores asociados y de estilo, secretaria, diseñadora, asistente editorial y encargados de la plataforma ha sido esencial para el desarrollo y mejoramiento continuo de la revista. Asimismo, el apoyo continuo de la Escuela de Psicología de la Pontificia Universidad Católica de Chile como institución que alberga a la revista ha sido fundamental para su continuidad y crecimiento. Un gran agradecimiento desde Psykhe a todas y todos ustedes.

En el ejercicio de rememorar, inevitablemente se abre también la perspectiva de futuro. Junto con consolidar los cambios realizados a nuestros procesos editoriales, esperamos seguir contando con una creciente contribución de trabajos provenientes de diversos países, y ya planeamos la edición de números especiales sobre temáticas que creemos serán de gran interés para la audiencia de Psykhe.

Durante estos 30 años Psykhe ha sido testigo y escenario de la evolución de la investigación en psicología y de los caminos que ésta ha ido construyendo. En este nuevo aniversario renovamos el compromiso de Psykhe para aportar, desde su rol de difusión y aseguramiento de estándares académicos y éticos en la investigación en psicología, a que el conocimiento generado por investigadoras e investigadores alcance impacto en los distintos campos disciplinares, y en último término, en la construcción de sociedades justas y orientadas a favorecer el bienestar y salud mental de las personas y los contextos en los cuales se desarrollan.

\author{
Christian Berger \\ Editor Psykhe \\ Enero 2022
}

